\title{
Research on the Construction of Economics Laboratory for T\&R Purpose
}

\author{
Zhaoyong Sun* \\ School of Economics and Management \\ Xi'an University of Technology \\ Xi’an, China \\ dakuamao@126.com
}

\author{
Wenxiu $\mathrm{Hu}$ \\ School of Economics and Management \\ Xi'an University of Technology \\ Xi'an, China \\ hwxsxj@sina.com
}

\begin{abstract}
Economics laboratories play a significantly supporting role in the process of teaching and research. It is of great importance to construct economics laboratories to promote teaching and research and avoid the waste of laboratory resources. In this paper, the economics laboratories are classified into two categories: theoretical ones and applied ones. And the functions and contents of construction of economics laboratory are described in detail. It is expected that the economic laboratory will greatly boost the quality of teaching and research.
\end{abstract}

Keywords-economics laboratory; innovation capability; teaching and research; Laboratory construction

\section{INTRODUCTION}

Teaching and research (T\&R) of economics theories tends to easily fall into the dilemma of "blackboard economics" as a result of ignoring the economic reality. Economics teachers have always focused on the imparting of economic theories to their students and neglected to cultivate innovation ability in their students. As a result of this, students rarely have any opportunity to participate in theoretical exploration and they accept theories passively. The great importance, however, has been attached to the cultivation of practical and innovation ability in higher education. While doing research, economics teachers have difficulty testing their economic theories due to the lack of experimental data.

Nowadays, T\&R of economics theories are increasingly dependent on the economics experimental data and surveys. Economics experiments have become the main driving force of development of economics. In other words, the development of economics is increasingly dependent on game experiments or survey data. Many theoretical models in economics are based on various theoretical hypotheses, such as auction mechanism, principal-agent incentive theory, bargaining problem, voting theory and behavior evolution theory. Only by participating in designing and conducting experiments can students' practical and innovative ability be cultivated. Additionally the experimental results are more credible through the experimental simulation. With the design of new experiments and the accumulation of experimental data, economics will achieve further development.

With the rapid development of experimental Economics, a great number of universities and institutes around the world have built economic laboratories to promote the quality of

Supported by grants from Shaanxi Provincial Natural Science Fund (2014JM2-7136), Shaanxi Provincial Department of Education Project (16JK1529) and Xi'an Science and technology Fund(CXY1439(6)).
T\&R. How to construct economics laboratory is of critical importance to the cultivation of students' practical and innovative ability and to the promotion of economics research.

The process of economics T\&R relies on experimental cases and survey data, most of which come from current economic realities. Teachers and students can design economics experiments to simulate economics phenomena in economics labs. Economics experiments can be seen as the sources of cases and survey data. The whole process of experiments includes repeatable experiments design, model simulation, collecting and analyzing of survey data. Economics lab serves as a platform for teachers and students to participate in experiments. Therefore, a complete economics lab is expected to provide experimental environment and places for teachers and students.

\section{GOALS AND FUNCTIONS OF CONSTRUCTION OF ECONOMIC LABS}

\section{A. Goals of Economics Lab construction}

To cultivate students' innovative ability. Laboratory construction can supplement and extend teaching content, contribute to the enhancement of students' innovative and practical ability. Game experiment can improve students' interest in learning and deepen students' understanding of economics theories. Social and economic survey can promote students' reflection on social and economic issues and help students to grasp the methods of social and economic survey. The practice from theoretical modeling to simulation is the best way to stimulate students' innovative ability.

To give support to economics research. Game experiments have accumulated a large number of experimental data; socioeconomic survey can help students accumulate micro-survey data, which can significantly improve the level of teachers' economic research by providing data support for economics research. The process of experiments promotes the combination of theoretical research and practice and provides opportunities to keep up with the latest development of economics.

To perfect the teaching system of economics. Experimental teaching of economics is included in the experimental part of each course. Lacking coordination mechanism, experimental teaching cannot meet the requirements of students with strong 
innovation ability. In order to cultivate the innovative ability of economics major, economics lab with package training programs from experimental design to the data analysis, is the useful supplement to the current undergraduate teaching system of economics.

To enhance the reputation of universities. With the publication of game experiments and socio-economic survey research findings, the prestige of the university can be gradually promoted. And laboratory training will improve the possibilities of wining prizes in modeling contests and quantitative investment competitions on the part of students. It helps to raise the school reputation.

\section{B. Functions of Economics labs}

During the four years in university, students majoring in economics study such courses as microeconomics, macroeconomics, econometrics, development economics, regional economics, industrial economics, institutional economics, public economics, labor economics, and international economics. In the process of conventional teaching, most teachers pay more attention to the training of theoretical modeling. These theories should be tested by experiments. By designing experiments and simulating economic phenomena, the participants' choice can be observed, and equilibrium results analyzed.

The simple mathematical derivation in economics research is replaced by experimental and mathematical statistics. It helps to solve the problem that the previous empirical research is highly abstract, simple and inconsistent with the real world. The experiment can overcome the non-repeatability of previous empirical tests by creating a simulated environment, experimenting and re-verification, replacing historical data. We can manipulate the experimental variables and control the experimental conditions, which eliminates the impact of the non-critical factors on the experiment, thus avoiding passive acceptance of data in past empirical studies.

Economic and social phenomena are comprehensively described and explained through theory models, and the models are tested by survey data. In the empirical research, a large amount of survey data is needed. Social surveys can not only obtain survey data, but also help students pay attention to social and economic problems.

Economics lab is an auxiliary training system to cultivate students' practice and innovation ability. Cultivating students' professional practice ability and developing innovative ability should start with laboratory construction [1]. Students' innovative and practical abilities can be enhanced through experimental process. Experimental teaching of economics is an important part of students' practice.

\section{STATUS QUO OF ECONOMICS LABS}

Economics labs provide a platform and place for university teachers and students to conduct experimental research. It is expected that economic laboratory will greatly promote the research and teaching activities and play an important role in T\&R. But there exit many problems with economic labs in most universities. To name just a few,

\section{A. Institution is Imperfect}

Designing economics experimental project is a kind of highly creative work. Developing economics model to simulate socio-economic phenomena cannot be finished without teachers' and students' participation [2]. But in most universities, teachers and students do not engage in it [3]. Only in the long-term research and in-depth thinking, can they be qualified to the tasks. The academic research atmosphere is very important to the construction of economics labs.

Sound management institution is the indemnification of laboratory operation. The design of game experiment and policy simulation needs teachers and students' extensive participation. The task of design and simulation is highly creative. It is difficult to promote the work progress without incentives for teachers and students. To make laboratory work well, we should establish experiment schedule and laboratory regularly.

\section{B. The Content of Experiment is Simple}

Economics lab in many universities is nothing but a multimedia room with computers installed with various practical systems, such as "bank simulation system", "international trade declaration system" and so on. Practical operation can be trained in lab of this type. But economics experiments of economics cannot be carried out there. Teachers and students cannot conduct economics experiments to obtain experimental and survey data

\section{There is shortage of adequate fund Support}

Economics laboratory cannot be well-operated without sustained financial support. The routine work of laboratory consists of designing experiments, operating experiments, analyzing data, conserving experimental files, etc. All of these jobs require full-time staff to complete.

In order to simulate environment and make participants expose their real preferences, it's necessary to give winners cash incentives in the process of experiments. And the processes of social and economic survey cost much money. In addition to the purchase of computer equipment, economics laboratory's daily operation needs continuous fund support. But most economics laboratories in universities can only get modest amounts of funding. Due to the neglect of laboratory construction, most laboratories are difficult to obtain followup funds.

\section{THE CONTENT OF ECONOMICS LAB CONSTRUCTION}

In order to facilitate T\&R, economics labs should possess theoretical and practical research functions. Economics labs can be classified into theoretical economics labs and applied economics labs according to their function. The former one is composed of policy simulation laboratory and game laboratory while the latter consists of quantitative investment laboratory and socio-economic survey laboratory. Game experiments and policy simulations cannot work without theoretical model design. Developing economics models is the foundation of economics experiments. Quantitative investment laboratories and socio-economic survey laboratories are mainly for the 
cultivation of students' practical ability. The structure of economics labs can be seen in Fig1.

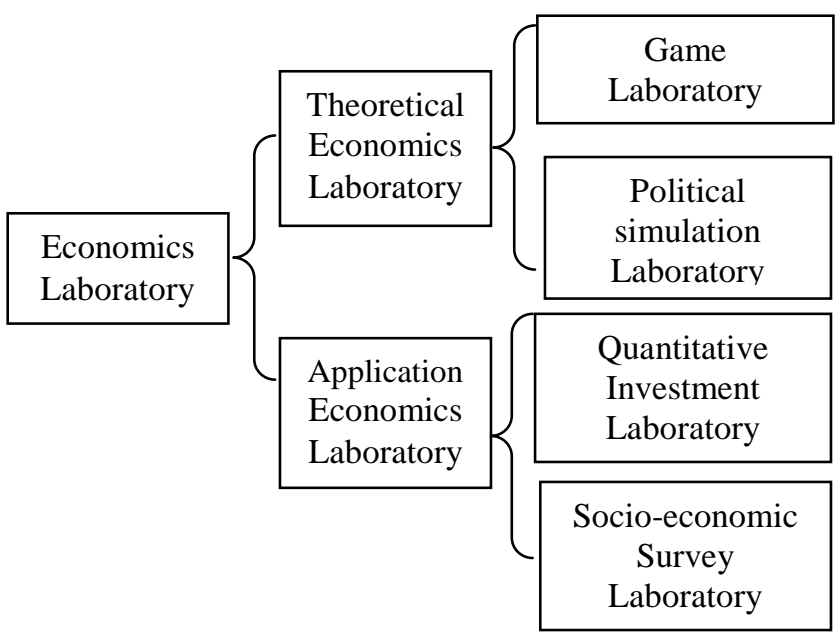

Fig. 1. Structure of Economics Laboratory

\section{A. Game Labs}

The game experiment is a practical simulation. The feasibility and value of economic theories can be tested by game experiments. Firstly, the equilibrium results should be analyzed according to the game models. Secondly, we should recruit students to participate in the experiments and observe behavior of the participants. Finally, the most important thing is to record the experimental results and compare the theoretical and experimental results.

1) Designing game experiments: The design of game experiment guide is an important part of the game laboratory. In order to transform complex phenomena into controllable laboratories, we should analyze the economic phenomena and establish an environment, including the initial endowments, preferences and costs that motivate exchange [4]. These experiments support the hypothesis of agents who are maximizers of utilities [5]. There are already many famous game models that have been experimented, such as bargaining game, auction game, public choice theory, principal-agent theory, kinds of evolutionary game and so on.

a) Bargaining theory: The participants are bargaining to gain more revenue under established rules. Bargaining theory explains the distribution of benefits by negotiation, which emphasizes their status or results.

b) Auction theory: Auction is an ancient market trading mechanism. Different auction processes and rules will lead to greatly different results. Auction theory is considered as mechanism design of forcing participants to show their preferences. Designing auction mechanism is still one of the hot issues in mechanism design.

c) Public choice theory: There are many theories and phenomena in public choice theory, such as voting paradox, free rider, tragedy of the commons etc.. These experiments are designed to test participants' rational choice and equilibrium results. d) Principal-agent theory: Design a contract to deal with various kinds of incentive and regulatory problems in information asymmetry or incomplete conditions.

e) Evolutionary game: Biological evolution is incorporated into the analysis of game theory to reveal the dynamic mechanism of population behavior change. Evolutionary game theory has been developed into a new field of economics gradually.

2) Controlling the experimental process: After designing game experiment, we should organize participants to start the experiment according to experimental guide. On the condition of keeping other conditions fixed and controlling variation of one variable, compare the difference of results [6]

a) Recruiting participants: Recruiting volunteers to participate in the game is necessary to organize the game experiment. Their choice in the experiment affects the results of the experiment directly.

b) Explaining the rules of the game: The participants make choices under established constraints. In order to let participants understand the rules of game, experimental designer must explain the rules of the game.

c) Organizing experiment: According to certain practical rules, we should give a certain amount of material compensation to experimental participation.

d) Analyzing the experimental results: At the end of the experiment, the participants' behaviors were observed and the experimental results were recorded . The difference between theoretical analysis and experimental results is analyzed. The accumulation of experimental evidence can be seen as informal evidence of this preference.

\section{B. Policy Simulation Laboratory}

Trade policy, environmental policy, tax policy and monetary policy have effects on the economic system. Policy simulation can comprehensively assess the effectiveness of policy implementation. It is necessary to analyze the impact of various policies based on various simulation models. Policy simulation laboratory provides a communication platform for teachers and students. The influence of government policy can be simulated and compared by all kinds of models. Nowadays, popular simulation method in economics research is system dynamics models and computable general equilibrium model. Policy simulation laboratory should start with the two kinds of model, and gradually introduce other simulation models.

1) System Dynamics models: System dynamics models are widely applied in economic research for seizing internal mutual feedback characteristics of the system. Developing system dynamics models to simulate economic system is a good way to train students' creativity.

2) Computable General Equilibrium model: The CGE model is applicable to the analysis of the influence of policy factors in the market economy. After we set the CGE model framework and calibrate the parameters, it can simulate the influence of various policies on the economy by optimizing the selection of families, enterprises and governments. 


\section{Quantitative Investment Laboratory}

Through daily teaching, students can learn lots of investment theories; they cannot grasp the quantitative investment method. At present, there is a big gap between teaching system and practice. It's necessary to hold a shortterm training course for quantitative investment and hold a school-level quantitative investment trading contest to train student's innovative ability. It's also necessary to test investment strategies' feasibility with history data.

1) Short-term training: Most students aren't familiar with commercial quantitative trading platform. Programming of MATLAB language is also a threshold for many students. To encourage students to participate in practice, we should provide short-term training for interested students.

2) Quantitative investment contest: The competition can stimulate students' interest in practice, and it's the best way to assess teaching effect. Organizing school competitions and encouraging students to participate in all kinds of national and social quantitative competition is an important content of laboratory construction.

\section{Socio-economic Survey Laboratory}

The purpose of setting up the laboratory is to provide survey data on income distribution, rural development, and rural governance. For the specific socioeconomic issues, recruit students to launch a questionnaire survey during the winter and summer vacations. As the investigation progresses, data is being accumulated and a database is formed.

1) Choosing social problems: More and more researches rely on initial data, and the lack of first-hand data becomes the barriers to research. First of all, we need collect and select hot social and economic problems and design questionnaires. At this stage, we should encourage teachers and students to combine social surveys with their research projects. The survey data will promote their research in turn.

2) Socio-economic questionnaire: Questionnaire survey is the primary way to obtain social and economic information. And participating in social and economic investigate is helpful for teachers and students to get out of ivory tower. New socioeconomic hot spots will be discovered during the survey. After selecting the investigators, it is necessary to train investigators who will conduct questionnaire survey.

3) Data analysis: In this period, the main task of teachers and students is to analyze the relevant data, and draw the research conclusion. With the analysis of data, important results will be found and published.

\section{GUARANTEE OF LABORATORY CONSTRUCTION}

\section{A. Improving the Management System of Labs}

In order to ensure the normal operation of the laboratory, the construction of sound management system should not be ignored. The design of experiment scheme, experimental operation guidance, the filing of experimental data and the release of experimental results need perfect system guarantee. The participation of teachers and students is of particular importance in the construction of laboratory. This requires a perfect management system to ensure that teachers and students participate in the construction of the laboratory.

Most economics laboratories are composed of game laboratory, policy simulation laboratory, quantitative investment laboratory and socio-economic survey laboratory. Because there is a great gap between the various fields of economics, each laboratory needs different teachers who engage in related research to manage it. The problems that teachers and students encountered in T\&R can be solved in the laboratory.

\section{B. Follow-up fund support}

Without continuous funding, economics laboratories cannot work properly. Different from subjects of the natural science laboratory, the subject of economics experiment is the individual with subjective initiative. The entire experimental process can not be implemented successfully without financial support. It is necessary to provide material incentives to participants in the game lab to make the experimental results credible and to simulate the economic environment. Other activities such as the survey in socio-economic survey laboratories and quantitative investment competition, will make laboratory operating costs go up.

\section{CONCLUSION}

The present study attempted to design a economics laboratory functional diagram to guide laboratory construction for T\&R. The perfect economic laboratory is a platform for teaching practice and scientific research. It can provide cases and survey data for economics theory teaching and economics research. The extensive participation of teachers and students and fund support are the necessary conditions for the construction of the economic laboratory. The teachers can combine the laboratory construction with the scientific research project to strive for more research funds for the laboratory construction.

\section{REFERENCES}

[1] XF. Li, HY. Qin, XC. Wu, CS.Y, WQ. Hou, "The Tentative Exploration on the Construction and Improvement of Economics Lab”, Experimental Technology and Mangement, 2007, 24 (7) : 1-6, (In Chinese).

[2] HY. Huang, "Discussion on the Construction of Laboratory of Economic and Management”, Management Observer, 2017, 639 (4) : 122-126, (In Chinese).

[3] XF. Wang, YQ. Zhang, "Thoughts and Practical Exploration on the Construction of Industrial Economics Laboratory", Theory and Practice of Contemporary Education, 2012, 4 (12), 115-117 (In Chinese).

[4] VL. Smith, "Economics in the Laboratory", Journal of Economic Perspectives, 1994, 8 (1) :113-31.

[5] K. Binmore, A. Shaked, "Experimental economics: Where next?", Journal of Economic Behavior \& Organization, 2010, 73 (1) : 87-100.

[6] F. Guala, "The Methodology of Experimental Economics," Cambridge University Press, 2005, volume 59 (2) : 247-252. 